\title{
Characteristics Identification of Myeloblast Cell Using K-Means Clustering for Uncontrolled Images
}

\author{
Retno Supriyanti, Ahmad Rifai, Yogi Ramadhani, and Wahyu Siswandari
}

\begin{abstract}
Blood cells are one of the most important parts in humans. One type of blood cells that play an important role in a leukemia diagnosis is leukocyte cells. There are some types of leukocyte i.e. myeloblast, lymphoblast, monoblasts and erythroblasts. One method of measuring leukocyte cell abnormalities is by examination of the morphology of leukocyte cells covering the area, circumference and diameter of leukocyte cells. In this research will be identified morphology of myeloblast cells by using K-means clustering method. The observed control variable is a characteristic of myeloblast cell that includes diameter, contour, and uniformity of object, amount, and cell density. While the observed data is uncontrolled image (noise) with RGB color format. The experiment showed promising results for further development.
\end{abstract}

Index Terms-Leukocyte cell, leukemia, morphology, K-means clustering, uncontrolled image.

\section{INTRODUCTION}

Blood is a fluid contained in the body of living things except plants, which serves to deliver substances and oxygen to the tissues of the body [1]. One type of blood cell is a leukocyte cell or commonly known as leukocytes. Abnormalities in leukocytes can refer to one type of fatal disease that is blood cancer or commonly known as leukemia. The diagnosis of leukemia is based on clinical signs and symptoms and investigations. Clinical signs and symptoms commonly found are malaise, fatigue, fatigue, pallor, frequent infection, heat, joint pain, full race in the abdomen, or abnormal bleeding. Laboratory investigations used to assist in the diagnosis are complete blood tests, peripheral blood morphology, bone marrow morphology, cytogenetics, DNA, and cluster of differentiation detection using flow cytometry [2]. For the developing countries such as Indonesia, Most laboratories still use cell morphology to help diagnose leukemia due to limited resources, both infrastructure and human resources. This check is cheaper. However, morphological examination requires the expertise of a limited number of clinical pathologists. This examination is sometimes less valid because in some cases it is difficult to distinguish blast cell morphology into the type of myeloblast, lymphoblast, monoblasts, or erythroblasts so that potential errors of diagnosis. Under the above conditions, it is

Manuscript received October 19, 2018; revised April 17, 2019.

Retno Supriyanti, Ahmad Rifai, and Yogi Ramadhani are with Electrical Engineering Dept, Jenderal Soedirman University. Kampus Blater, J1. Mayjend Sungkono KM 5, Blater, Purbalingga, Jawa Tengah, Indonesia (e-mail : retno_supriyanti@unsoed.ac.id).

Wahyu Siswandari is with Medical Department, Jenderal Soedirman University, Jl. Gumbreg, Purwokerto, Jawa Tengah, Indonesia. necessary to develop an automatic blood cell type detection device as a low-cost, easy-to-use and accurate leukemia diagnostic tool so that it can be distributed across all healthcare units throughout Indonesia and in particular to remote areas. One solution to solve this problem is the use of digital image processing techniques for morphology identification of leukocyte cells. In our previous research [3]-[9] we developed simple and easy-to-use system for handling problems about health services in rural areas by implementing image processing techniques in the case of cataract diseases, pregnancy diagnosis, and dental segmentation.

There are several studies that use digital image processing techniques in the identification of blood cells. Putzu [10] in his research conducted segmentation using thresholding. One post segmentation process is the grouping of single objects and pitch object as well as the separation of coincident cells. Ajala [11] conducted a comparative study for edge-detection and watershed-based segmentation analysis. Edge detection methods are used to obtain ridges, lines and contours along red blood cells. While the Watershed method includes opening and closing reconstruction on the overlapping images. The results show that segmentation by using watershed method is better than edge-based detection. Higgins [12] analyzed the relationship of blood flow and the environment due to varied blood cell variations. He uses image morphology computations and machine learning algorithms to measure fluctuations in flow velocity. Stadelmann [13] identifies an automatic calculation number of leukocyte cells using the Ada Boost method. The result is a real time automatic system to calculate the number of leukocyte cells in a scan using a microscope. Guo [14] did research with leukocyte cell in bone marrow using multispectral imaging technique. For image segmentation he uses the Support Vector Machine (SVM) which is applied directly to the spectrum of each pixel of the microscopic image. Gual-Arnau [15] did research on the red blood cell object in particular is a sickle cell. These sickle cells cause erythrocyte-containing hemoglobin polymerization. $\mathrm{He}$ focused his research on sickle cell shape changes using integral-geometry method, active-contour segmentation method and k-NN classification method. Alferez [16] developed a method of introducing various types of lymphoid cells automatically. In his research he used the component clustering and watershed transformation in segmenting the image. Kaewkamnerd [17] in his research, he developed automated equipment for the detection and classification of malarial parasite species using the image of blood cells. The system he developed uses image-processing analysis combined with motorized unit hardware mounted on a microscope. This is done to get a quality microscopic image 
to get accurate image analysis. Heo [18] he developed a real time image processing pipeline to produce excellent quality microscopic images in a micro fluid chip. Yang [19] in his research, he developed simple, inexpensive and portable equipment to detect the amount of Plasmodium Falciparum that infects blood. The tools he developed are able to classify all types of parasites present and have high sensitivity. De Vylder [20] In his research, he applied the active contour method for the detection of the nucleus of blood cells. He modified the approach used by defining a dictionary based approach formulated in the optimization of energy functions. Pang [21] did research on 3D image processing on mouse cell tissues that do not have immunity. 3D image reconstruction is done by using microvascular tissue and calculating the viscosity of blood cells. Fang [22] did research for blood cell classification using comparability theory. To reduce the effects caused by diffraction and an incoherent source, the blood cells are placed close to the sensors used for the data acquisition, then performed a comparison with the observed blood cells using a microscope. Doubrovski [23] he developed an acousto-optic method for the classification of blood cells based on digital image analysis of red blood cells and their aggregates and their complex immune. Solder [24] he successfully analyzed the morph-functional microvascular processing of living organs in human placenta. Antoine [25] he developed a methodology that combines the concept of image pre-processing and measurement of particle image velocimetry (PIV) to produce measurable speed in an experiment. Park [26] his study became a reference in measuring PVI x-rays from a bloodstream in animals and analyzing hemodynamic characteristics and blood circulation of the disease. Lyulko [27] he developed a device, which is used to analyze blood lymphocytes using an algorithm based on dual fluorescent labeling with separate cytoplasmic and nuclear image analysis. Kaliviotis [28] his research discussed about the distribution of red blood cell aggregates in a T-shaped bifurcation in large scale micro vessel. Navalta [29] he describes an image-based approach using computer software on lymphocytes to overcome the impasse on the implementation of morphological methods.

Referring to the research that already conducted as explained in the above paragraph, all the processes and results of the research will be carried out in an area that has adequate health facilities. However, when dealing with problems in rural areas such as those found in many developing countries such as Indonesia, this will be a significant problem. Many regions in Indonesia do not have adequate health facilities, including human resources who are competent in the medical field, one of whom is a clinical pathologist. Many regions in Indonesia do not have adequate health facilities, including human resources who are competent in the medical field, one of whom is a clinical pathologist. Clinical pathologists are required in the analysis of abnormalities in blood cells. With the limited number of clinical pathologists, one solution is to develop a tool that can replace some of its tasks in the clinical analysis of blood cells. According to this case, the goal of our research is to develop a simple and easy-to-use system for analyzing characteristics of myeloblast cell using image processing techniques, in order to solve limitation of health services in developing countries such as in Indonesia. In previous work [30]-[33] we did experiment for contour measuring of myeloblast cell using morphological image. The result is promising for further development therefore, in this paper we develop this system by measuring area, circumference, diameter and texture analysis for myeloblast cell.

\section{METHODS}

\section{A. Segmentation Process}

Segmentation process is dividing image into multiple regions or objects. In this research we use K-Means method by dividing regions into 3 areas based color intensity and similarity.

In the image segmentation and arithmetic calculation process, image characteristic is divided into 3 types of sub mode, which is for image type 1, type 2 and type 3 based on intensity difference. Image type 1 , nucleus color is reddish, enveloped by a nucleus that is almost the same color as the color of red blood cells. In addition, type 1 also has a far distance of image retrieval, so it will have a smaller morphological parameter value than type 2 and 3 . Type 2 has a dark purple nucleus color with a red-purple cytoplasm color. In this type the color of the cytoplasm is different from the red blood cells, so in the measurement of cytoplasmic morphological variables becomes easier. The distance of this image is very close, so the area, circumference and diameter will be larger than type 1 . Type 3 is similar to type 1 in color distribution, but judging from the way its image is taken, the image of this type is similar to type 2 . Fig. 1 shows all three types of this image.

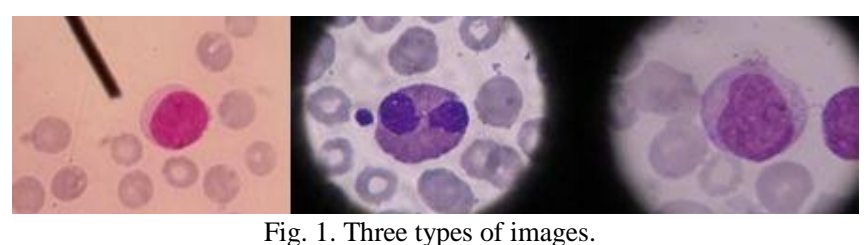

The image will be separated by seeing the color difference of the very prominent nucleus of reddish purple. The advantage of the K-Means method of segmenting the nucleus is its very contrasting color with red blood cells and the cytoplasm causing the accuracy sufficient to separate the nucleus from the rest. By changing the background to be 0 (black), then the arithmetic calculation process characteristic of the image becomes better.

\section{B. K-Means Segmentation}

$\mathrm{K}-\mathrm{Means}$ is a clustering method that can distinguish certain objects into groups. In this research the RGB image is converted to $L \times a \times b$ image form and the result will be grouped into 3 clusters based on their similarity. The level of similarity of each pixel is taken based on its color spread. Before clustering is done, the image converted to $L \times a \times b$ will be reshape first. The function of reshape is to return the column and row values in the myeloblast cell matrix array. Then the image converted into the array will be segmented into 3 clusters using K-Means Clustering. After the image segmentation into three clusters, each segmented image will be labeled. Then from the label will be taken segmented image as a filler on the empty array cell. Each image is made according to the number of clusters which is 3 . The process of 
clustering is basically just calculate the intensity of color by using the distance Euclidean each pixel to another pixel and done repeatedly on the other centroid, so that will get the smallest distance value between one point to another. By determining the number of clusters to be 3 , then there will be 3 centroid image that used as point of calculation parameter. In the clustering process as segmentation it will take a segmented area that has the smallest area width on the image types 1 and 2, and will be the maximum segmented image area for image type 3 .

\section{Morphological Analysis}

At this stage we discuss the processing of myeloblast cell images seen from the state of morphology. The variables included are image area, image circumference, and image diameter (nucleus and cytoplasm).

A simple way to calculate the area of an object is by counting the number of pixels on the object [34]. This pixel calculation is done by converting the image to binary, so it becomes a two dimensional matrix. The two dimensional matrices will be initialized as rows and columns. Then calculated matrix rows and columns to read the number of pixels in the image, so as to obtain the area of the image in units of pixels. Fig. 2 describes the calculation of myeloblast cell area in this research.

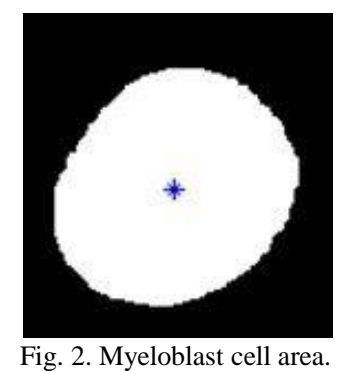

In this experiment the circumference is used to find the binary edge of a nucleus image of myeloblast cells. In the manual calculations to determine the circumference of myeloblast cell image in principle is the same as calculating the area of the image, it's just done the first edge detection algorithm that has been covered in the circumference function as described in Fig. 3.

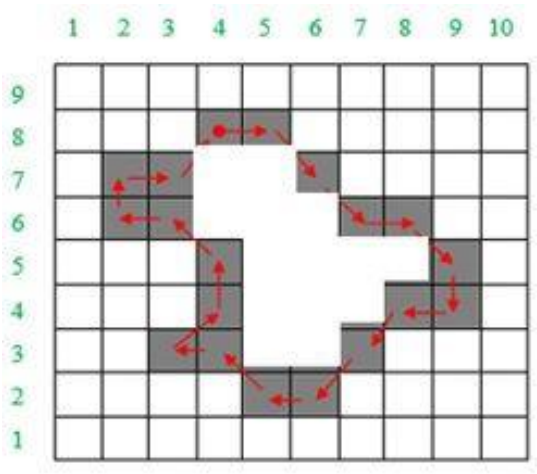

Fig. 3. Image circumference.

Based on Fig. 3 we can calculate the image circumference with Equation 1.

$$
\text { Perimeter }=\sum_{\text {Length }(L)=0}^{L-1} \text { Pixels }
$$

In this experiment the diameter is taken from the average distance per pixel edge where the approximation is done by calculating a quarter of the area of the myeloblast cell image which is squared as shown in Equation 2.

$$
\text { Diameter }=\frac{1}{4} \operatorname{sqrt}(\text { Area })
$$

\section{Texture Analysisi}

Texture analysis is one type of feature extraction based on the image statistics feature. Texture analysis can be done by first order feature extraction method, extraction of second order feature, Gabor filter, wavelet transformation, and etc. [34]. Texture analysis can be done by using statistic approach, matrix co-occurrence or using the GLCM method. In this research analysis is done by using statistical approach. Texture features exploited in this experiment are mean, contrast, smoothness, third moment, uniformity, and entropy. Mean is the mean of intensity. In this experiment is the average spread of color intensity in a grayscale nucleus form of myeloblast cells and described in Equation 3.

$$
\mu n=\sum_{i=0}^{L-1} Z i P(Z i)
$$

Smoothness or softness is a measure of the relative softness of intensity in the region. $R$ is 0 for regions in constant intensity and close to 1 for regions with large excursions in intensity level values and described in Equation 4 [34].

$$
R=1-\frac{1}{1+\sigma^{2}}
$$

Skewness is a histogram-sized measure of an image, in this case the bias of the myeloblast cell image histogram. This size has a value of 0 for a symmetrical image, positive for right-lean and negative images for left-sided image histograms and described in Equation 5 [34].

$$
\mu_{3}=\sum_{i=0}^{L-1}\left(Z_{i}-m\right)^{3}-P\left(Z_{i}\right)
$$

Uniformity is a measure that compares the gray level of the myeloblast image with the gray image level when the maximum condition and described in Equation 6 [34].

$$
U=\sum_{i=0}^{L-1} P^{2}\left(Z_{i}\right)
$$

Entropy is a moment that states the content of information contained in an image, so that will be found value randomness image based on the degree of similarity. It's described in Equation 7 [34].

$$
e=\sum_{i=0}^{L-1} P\left(Z_{i}\right) \log _{2} P\left(Z_{i}\right)
$$

\section{RESUlTS AND DISCUSSION}

As discussed in Subsection II.B, the process of clustering is basically just calculate the intensity of color by using the distance Euclidean each pixel to another pixel and done repeatedly on the other centroid, so obtained the smallest 
distance value between one point to another. By determining the number of clusters to be three, there will be three centroid images that are used as a parameter point. In the clustering process as segmentation it will take the segmented area which has the smallest area width in the image types 1 and 2, and will be taken the maximum segmented image area for image type 3 . This relates to the spread of different color intensity between each type of image, and differences in image retrieval distance, thus requiring slightly different segmentation programs. Table I shows an example of clustering process.

TABLE I: AN EXAMPLE OF CLUSTERING PROCESS

\begin{tabular}{|l|c|c|c|}
\hline Original Image & Cluster 1 & Cluster 2 & Cluster 3 \\
\hline & &
\end{tabular}

Referring to Table I, the image on the 3rd cluster clearly shows that the image is the smallest area in the original image cropping. The image of this segmentation will be processed and converted into grayscale image to observe the texture characteristics, besides the image will also be converted to binary image form for morphological analysis. Table II shows some examples of image segmentation result.

TABLE II: SEGMENTATION RESULTS

\begin{tabular}{|c|c|c|c|c|c|}
\hline No & $\begin{array}{c}\text { File } \\
\text { Name }\end{array}$ & Cropping & L*a*b & K-Means & Binary \\
\hline 1 & AF3 & & & & \\
\hline 2 & AF0 & & & & \\
\hline 3 & P341 & & & & \\
\hline
\end{tabular}

Based on the results of the segmentation process in Table II, it can be seen that the original image has different color depth and pixel values depending on the distance of the capture and the type of camera. In image type1, has a large image retrieval distance resulting in less precise result segmentation. Segmentation results sometimes still contain pixels from other parts of the myeloblast image, commonly called noise as shown in Fig. 4.

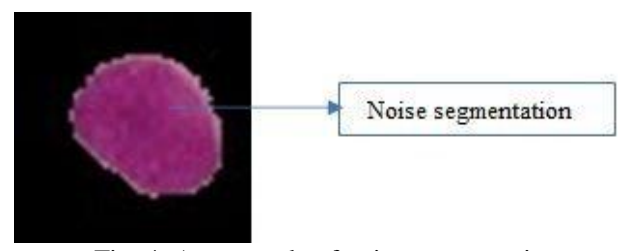

Fig. 4. An example of noise segmentation.

This noise will greatly influence on morphological analysis such as calculation of area, circumference, and diameter including also influence on texture analysis. However, when viewed from the color spread, image type 1 has a good color sharpness, but because the small pixel value then makes this type more susceptible to noise. Different things for image type 2 and type 3 . The types use the camera with a closing distance to the closer blood cell image objects, and has excellent quality results, resulting in more precise segmentation results, and has better morphological and texture analysis results as described in Fig. 5.

TABLE III: IMAGE MORPHOLOGY DATA

\begin{tabular}{|c|c|c|c|c|}
\hline $\begin{array}{c}\text { File } \\
\text { Name }\end{array}$ & Area & $\begin{array}{l}\text { Circum } \\
\text { ference }\end{array}$ & $\begin{array}{c}\text { Nucleus } \\
\text { Diameter. }\end{array}$ & $\begin{array}{c}\text { Cyto } \\
\text { Diameter }\end{array}$ \\
\hline $\mathrm{AF} 1$ & 10754 & 380.288 & 117.015 & 122.553 \\
\hline $\mathrm{AF} 2$ & 11146 & 382.621 & 119.128 & 148.801 \\
\hline AF3 & 10161 & 360.804 & 113.743 & 176.659 \\
\hline AF4 & 33013 & 922.688 & 205.021 & 276.301 \\
\hline AF5 & 8948 & 346.241 & 106.738 & 166.002 \\
\hline AF6 & 1800 & 155.488 & 47.8731 & 62.6022 \\
\hline AF7 & 1712 & 165.23 & 46.6882 & 62.4188 \\
\hline AF8 & 1734 & 149.253 & 46.9872 & 68.5531 \\
\hline AF9 & 1756 & 150.823 & 47.2843 & 62.5004 \\
\hline AF10 & 1747 & 149.144 & 47.163 & 53.8675 \\
\hline P1S1c. & 968269 & 3698.8 & 1110.33 & 1419.72 \\
\hline P1S3-4c & 856677 & 3467.86 & 1044.39 & 1290.04 \\
\hline P1S5bc & 589257 & 2857.7 & 866.179 & 972.453 \\
\hline P1S2c. & 936386 & 3605.9 & 1091.9 & 654.984 \\
\hline P1S5s & 50418 & 1167.76 & 253.366 & 283.524 \\
\hline P1S3-4s & 19450 & 530.692 & 157.367 & 165.983 \\
\hline P1S2s & 28015 & 603.057 & 188.865 & 254.584 \\
\hline P1S1s & 17190 & 473.737 & 147.943 & 179 \\
\hline F0 (11) & 243447 & 1902.17 & 1902.17 & 1187.88 \\
\hline F0 & 243179 & 1902.59 & 556.44 & 1187.88 \\
\hline $\mathrm{P} 2.16$ & 238027 & 1776.66 & 550.514 & 641.602 \\
\hline $\mathrm{P} 2.17$ & 243509 & 1772.06 & 556.817 & 626.134 \\
\hline $\mathrm{P} 2.18$ & 238860 & 1797.42 & 551.476 & 582.21 \\
\hline P2.19 & 216100 & 1709.87 & 524.545 & 604.515 \\
\hline $\mathrm{P} 2.20$ & 204135 & 1651.42 & 509.816 & 569.12 \\
\hline P2.21 & 220415 & 1723.54 & 529.756 & 672.718 \\
\hline $\mathrm{P} 2.22$ & 204293 & 1626.56 & 510.014 & 522.276 \\
\hline $\mathrm{P} 2.23$ & 206702 & 1646.51 & 513.012 & 567.006 \\
\hline P2.24a & 240947 & 1771.72 & 553.88 & 644.345 \\
\hline $\mathrm{P} 2.24 \mathrm{~b}$ & 243890 & 1780.85 & 557.253 & 731.728 \\
\hline P2.25. & 226782 & 1718.32 & 537.353 & 630.371 \\
\hline P3.26 & 157649 & 1450.97 & 448.023 & 141.309 \\
\hline P3.27 & 147026 & 1381.66 & 432.665 & 523.123 \\
\hline P3.28 & 142893 & 1569.67 & 426.541 & 436.965 \\
\hline P3.29 & 175088 & 1515.19 & 472.154 & 547.42 \\
\hline P3.30 & 133928 & 1469.62 & 412.944 & 615.087 \\
\hline P3.31 & 122638 & 1256.19 & 395.155 & 454.085 \\
\hline P3.32 & 122742 & 1277.53 & 395.323 & 626.25 \\
\hline P3.33-34 & 165940 & 1473.06 & 459.654 & 603.262 \\
\hline P3.35 & 155.488 & 155.488 & 47.8731 & 62.6022 \\
\hline P3.36 & 123854 & 1289.88 & 397.109 & 440.941 \\
\hline P3.37 & 142205 & 1368.05 & 425.513 & 502.193 \\
\hline P3.38 & 145490 & 1390.33 & 430.399 & 479.08 \\
\hline P3.39 & 138884 & 1344.94 & 420.515 & 488.264 \\
\hline P3. 40 & 145684 & 1380.75 & 430.686 & 496.698 \\
\hline P3.41 & 108258 & 1198.09 & 371.266 & 423.335 \\
\hline P3.43 & 78416 & 1420.99 & 315.978 & 638.5 \\
\hline P3.44 & 135089 & 1333.79 & 414.73 & 486.388 \\
\hline P3.45 & 143937 & 1367.66 & 428.096 & 505.033 \\
\hline
\end{tabular}

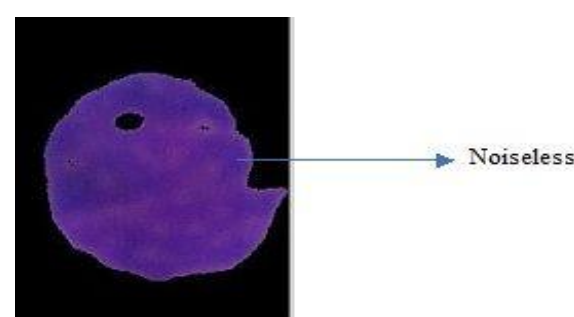

Fig. 5. An example of noiseless segmentation.

Referring to the discussion in Subsection II.C, the 
variables that are explored in the morphological analysis include area, diameter and circumference. Manually we can calculate the area of the image by summing each row by row of the image having pixel value 1 on the binary image of the segmentation result. It's described in Equation 8.

$$
\text { area }=\sum_{\text {row }=0}^{\text {row }=n} \text { the number of pixel rows to }(n)
$$

While for the calculation of diameter and circumference is complete discussed in Subsection II.C.

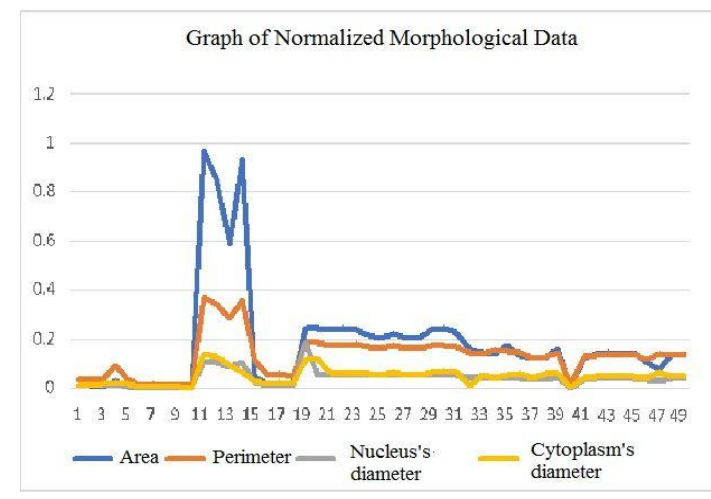

Fig. 6. Graph of normalization of each type of image.

Referring to Table III, there is a very high spike in some sample data. The highest jump is obtained from the image type 2 which makes the image with a very close distance and has a very high resolution camera value, so it has a very high value on each variable data. But in principle, in each image variable obtained almost identical results on one type of image. In the image type 1 looks to have the average value of each data is lowest. For image type 3, almost equal to the average of each control variable. Fig. 6 shows the normalization graph in the sample data we used in this experiment.

Referring to Fig. 6, a representation of the area, circumference, nucleus diameter, and the cytoplasm diameter of the image show the same comparison results in the image type. It also appears that image type 2 has excellent image quality and pixel value, and image type 1 has a very low image quality result.

In texture analysis, as discussed In Subsection II.D, we measured several variables in statistical texture. Table IV show the example results of our experiments.

Referring to Table IV, on the whole test data, we can create a grouping diagram based on static texture variable values as shown in Fig. 7.

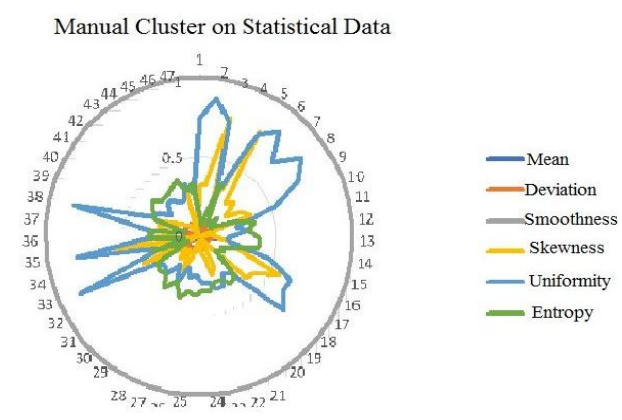

Fig. 7. Manual static texture data clustering.

In this grouping only the uniformity and skewness values satisfy the formation of image clusters. In image clustering, what is really needed is a uniformity value, where this value determines the uniformity of one image object with another image, so that the image that has the same characteristics will be grouped into one particular cluster and another uniform image will be grouped into one cluster.

TABLE IV: EXAMPLES OF OBESERVED VALUES OF TEXTURE VARIABLES
\begin{tabular}{|l|l|l|l|l|l|l|l|}
\hline File & Mean & Dev & Smoothness & Skewness & Uniformity & Entropy & Class \\
\hline AF1. & 21.6 & 53.6 & 0.999652 & 320658 & 0.7400 & 1.2759 & 0 \\
\hline AF2.. & 12.0 & 45.4 & 0.999515 & 328527 & 0.8729 & 0.6676 & 0 \\
\hline AF3.. & 28.9 & 71.8 & 0.999806 & 770735 & 0.7411 & 1.2717 & 0 \\
\hline F0.. & 40.4 & 43.5 & 0.999472 & 20937.9 & 0.2835 & 3.6183 & 1 \\
\hline P2.16. & 71.5 & 84.8 & 0.999861 & 213686 & 0.3466 & 3.0951 & 1 \\
\hline P2.17. & 74.5 & 89.0 & 0.999874 & 256007 & 0.3507 & 3.0486 & 1 \\
\hline P2.18. & 79.7 & 87.0 & 0.999868 & 125085 & 0.2987 & 3.5337 & 1 \\
\hline P2.16. & 71.5 & 84.8 & 0.999861 & 213686 & 0.3466 & 3.0951 & 1 \\
\hline P2.17. & 74.5 & 89.0 & 0.999874 & 256007 & 0.3507 & 3.0486 & 1 \\
\hline P2.18. & 79.7 & 87.0 & 0.999868 & 125085 & 0.2987 & 3.5337 & 1 \\
\hline P2.19. & 79.8 & 86.0 & 0.999865 & 102721 & 0.2942 & 3.4337 & 1 \\
\hline P2.21. & 89.9 & 87.5 & 0.99987 & -27936 & 0.2437 & 3.7052 & 1 \\
\hline
\end{tabular}

\section{CONCLUSIONS}

In principle, image morphology variables such as diameter, area and circumference for the early stages of the development of computer aided diagnostic devices are promising enough to identify myeloblast cell types. Although for further development still required the exploitation of other morphological variables as well. Likewise, the texture analysis provides a significant value in cell identification. For further research we will identify the type of lymphoblast cells, to find fundamental differences in characteristics with myeloblast cells.

\section{ACKNOWLEDGMENT}

We would like to thank the Pathology laboratory, "Prof. Dr.
Margono Soekardjo" Hospital for the data that is permitted to be used in this research. The research was funded by the Ministry of Research, Technology and Higher Education, Republic of Indonesia through the "Penelitian Strategis Nasional Institusi" scheme.

\section{REFERENCES}

[1] T. E. Moschandreou, Blood Cell - An Overview of Studies in Hematology, Ontario, Canada: Intech, 2012.

[2] M. Pokharel, "Leukemia: A review article," Int. J. Adv. Res. Pharm. Bio Sci., vol. 2, no. 3, pp. 397-407, 2012.

[3] R. Supriyanti, S. A. Priyono, E. Murdyantoro, and H. B. Widodo, "Histogram Equalization for improving quality of low-resolution ultrasonography images," Telkomnika (Telecommunication Comput. Electron. Control., vol. 15, no. 3, pp. 1397-1408, 2017.

[4] R. Supriyanti, U. Erfayanto, Y. Ramadhani, E. Murdyantoro, and H. B. Widodo, "Blood pressure mobile monitoring for pregnant woman 
based android system," IOP Conf. Ser. Mater. Sci. Eng., vol. 105, no. 1, 2016.

[5] R. Supriyanti, S. Suwitno, H. B. Widodo, and T. I. Rosanti, "Brightness and contrast modification in ultrasonography images using edge detection results," Telkomnika (Telecommunication Comput. Electron. Control., vol. 14, no. 3, pp. 1090-1098, 2016.

[6] R. Supriyanti, A. S. Setiadi, Y. Ramadhani, and H. B. Widodo, "Point processing method for improving dental radiology image quality," Int. J. Electr. Conputer Eng., vol. 6, no. 4, pp. 1587-1594, 2016.

[7] R. Supriyanti, D. Putri, E. Murdyantoro, and H. B. Widodo, "Comparing edge detection methods to localize uterus area on ultrasound image," in Proc. International Conference of Instrumentation, Communications, Information Technology, and Biomedical Engineering, 2013, pp. 152-155.

[8] R. Supriyanti, H. Habe, M. Kidode, and S. Nagata, "A simple and robust method to screen cataracts using specular reflection appearance," in Proc. SPIE 6915 Medical Imaging, 2008.

[9] R. Supriyanti, H. Habe, M. Kidode, and S. Nagata, "Extracting appearance information inside the pupil for cataract screening," in Proc. 11th IAPR Conference on Machine Vision Applications, 2009, pp. 342-345.

[10] L. Putzu and C. Di Ruberto, "White blood cells identification and counting from microscopic blood image," Int. J. Medical, Heal. Biomed. Bioeng. Pharm. Eng., vol. 7, no. 1, pp. 15-22, 2013.

[11] F. A. Ajala, O. D. Fenwa, and M. A. Aku, "A comparative analysis of watershed and edge based segmentation of red blood cells," Int. J. Med. Biomed. Res., vol. 4, no. 1, pp. 1-7, 2015.

[12] J. M. Higgins, D. T. Eddington, S. N. Bhatia, and L. Mahadevan, "Statistical dynamics of flowing red blood cells by morphological image processing," PLoS Comput. Biol., vol. 5, no. 2, 2009.

[13] J. V. Stadelmann and I. N. Spiridonov, "Boosting-based method for automatic detection of leukocytes in blood smear images," Biomed. Eng. (NY)., vol. 46, no. 4, pp. 164-166, 2012.

[14] N. Guo, L. Zeng, and Q. Wu, "A method based on multispectral imaging technique for White Blood Cell segmentation," Comput. Biol. Med., vol. 37, no. 1, pp. 70-76, 2007.

[15] X. Gual-Arnau, S. Herold-García, and A. Simó, "Erythrocyte shape classification using integral-geometry-based methods," Med. Biol. Eng. Comput., vol. 53, no. 7, pp. 623-633, 2015.

[16] S. Alferez, A. Merino, L. Bigorra, L. Mujica, M. Ruiz, and J. Rodellar, "Automatic recognition of atypical lymphoid cells from peripheral blood by digital image analysis," Am. J. Clin. Pathol., vol. 143, no. 2, pp. 168-176, 2015.

[17] S. Kaewkamnerd, C. Uthaipibull, A. Intarapanich, M. Pannarut, S. Chaotheing, and S. Tongsima, "An automatic device for detection and classification of malaria parasite species in thick blood film," $B M C$ Bioinformatics, vol. 13, no. Suppl 17, p. S18, 2012.

[18] Y. J. Heo, D. Lee, J. Kang, K. Lee, and W. K. Chung, "Real-time Image Processing for microscopy-based label-free imaging flow cytometry in a microfluidic chip," Sci. Rep., vol. 7, no. 1, p. 11651, 2017.

[19] D. Yang, G. Subramanian, J. Duan, S. Gao, L. Bai, R. Chandramohanadas, and Y. Ai, "A portable image-based cytometer for rapid malaria detection and quantification," PLoS One, vol. 12, no. 6 , pp. 1-19, 2017.

[20] J. De Vylder, J. Aelterman, T. Lepez, M. Vandewoestyne, K. Douterloigne, D. Deforce, and W. Philips, "A novel dictionary based computer vision method for the detection of cell nuclei," PLoS One, vol. 8, no. 1, 2013.

[21] Y. Pang, O. Tsigkou, J. A. Spencer, C. P. Lin, C. Neville, and B. Grottkau, "Analyzing structure and function of vascularization in engineered bone tissue by video-rate intravital microscopy and 3D image processing," Tissue Eng. Part C Methods, vol. 21, no. 10, pp. 1025-1031, 2015.

[22] Y. Fang, N. Yu, R. Wang, and D. Su, "An on-chip instrument for white blood cells classification based on a lens-less shadow imaging technique," PLoS One, vol. 12, no. 3, pp. 1-15, 2017.

[23] V. A. Doubrovski and M. F. Medvedeva, "The acousto-optical method for blood typing based on discrete processing of photographic images," Biomed. Eng. (NY)., vol. 50, no. 2, pp. 78-83, 2016.

[24] E. Sölder, C. Kremser, I. Rohr, P. Hutzler, and P. Debbage, "Molecular mapping deep within a living human organ: Analysis of microvessel function on the timescale of seconds and with sub-micrometre spatial resolutio," Histochem. Cell Biol., vol. 131, no. 5, pp. 537-551, 2009.

[25] E. Antoine, C. Buchanan, K. Fezzaa, W. K. Lee, M. Nichole Rylander, and P. Vlachos, "Flow measurements in a blood-perfused collagen vessel using x-ray micro-particle image velocimetry," PLoS One, vol. 8, no. 11, 2013.
[26] H. Park, E. Yeom, and S. J. Lee, "X-ray PIV measurement of blood flow in deep vessels of a rat: An in vivo feasibility study," Sci. Rep., vol. 6, no. 1, p. 19194, 2016.

[27] O. V. Lyulko, G. Garty, G. Randers-Pehrson, H. C. Turner, B. Szolc, and D. J. Brenner, "Fast Image analysis for the micronucleus assay in a fully automated high-throughput biodosimetry system," Radiat. Res., vol. 181, no. 2, pp. 146-161, 2014.

[28] E. Kaliviotis, J. M. Sherwood, and S. Balabani, "Partitioning of red blood cell aggregates in bifurcating microscale flows," Sci. Rep., vol. 7, no. February, p. 44563, 2017.

[29] J. W. Navalta, R. Mohamed, A. El-Baz, B. K. McFarlin, and T. S Lyons, "Exercise-induced immune cell apoptosis: Image-based model for morphological assessment," Eur. J. Appl. Physiol., vol. 110, no. 2, pp. 325-331, 2010.

[30] R. Supriyanti, G. Satrio, Y. Ramadhani, and W. Siswandari, "Contour detection of leukocyte cell nucleus using morphological image," $J$. Phys. Conf. Ser., vol. 824, no. 1, 2017.

[31] R. Supriyanti, M. M. Afif, I. T. Hasan, Y. Ramadhani, and W. Siswandari, "A simple tool for identifying outer shape of white blood cell based on image processing techniques in order to develop health facilities in developing countries," PONTE Int. Sci. Res. J., vol. 73, no. 12, pp. 314-325, 2017

[32] R. Supriyanti, A. Chrisanty, Y. Ramadhani, and W. Siswandari, "Computer aided diagnosis for screening the shape and size of leukocyte cell nucleus based on morphological image," Int. J. Elecetrical Comput. Eng., vol. 8, no. 1, pp. 150-158, 2018.

[33] R. Supriyanti, B. L. Nababan, Y. Ramadhani, and W. Siswandari, "A simple and easy-to-use tool for detecting outer contour of leukocytes based on image processing techniques," in Proc. 19th International Conference on Biomedical Applications and Bioinformatics, 2017.

[34] R. C. Gonzalez and R. E. Woods, Digital Image Processing, New Jersey: Prentice Hall, 2002.

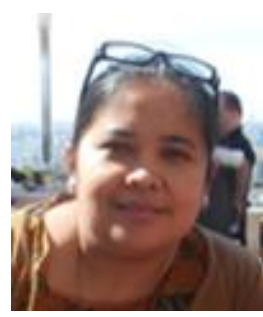

Retno Supriyanti is an academic staff at Electrical Engineering Department, Jenderal Soedirman University, Indonesia. She received her $\mathrm{PhD}$ in March 2010 from Nara Institute of Science and Technology Japan. Also, she received her M.S degree and bachelor degree in 2001 and 1998, respectively, from Electrical Engineering Department, Gadjah Mada University Indonesia. Her research interests include image processing, computer vision, pattern recognition, biomedical application, e-health, tele-health and telemedicine.

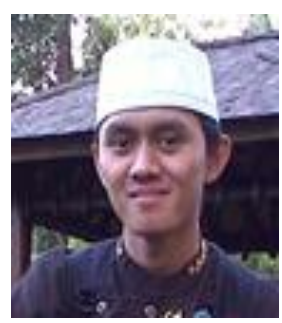

Ahmad Rifai was a student of Electrical Engineering Department, Jenderal Soedirman University. He received his bachelor degree from Electrical Engineering Depratment, Jenderal Soedirman University Indonesia. His research interest is image processing and pattern recognition. In this project he worked under the supervision of the first author of this article.

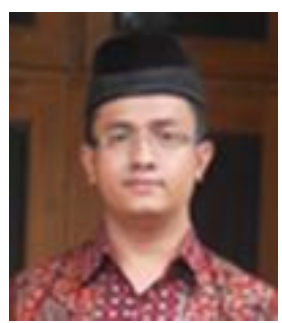

Yogi Ramadhani is an academic staff at Electrical Engineering Department, Jenderal Soedirman University, Indonesia. He received his MS Gadjah Mada Universirt Indonesia, and his bachelor degree from Jenderal Soedirman University Indonesia. His research interest including computer network, decision support syetem, telemedicine and medical imaging.

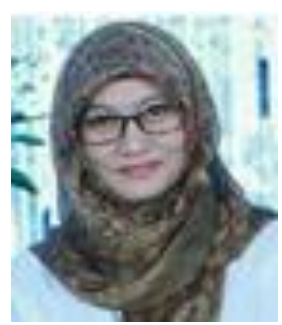

Wahyu Siswandari is an academic staff at Medical Department, Jenderal Soedirman University, Indonesia. She received her Ph.D from Gadjah Mada University. Also She received his M.S degree and bachelor degree from Diponegoro Indonesia. Her research interest including Pathology, e-health and telemedicine. 